\title{
Research on Entrepreneurial Executive Ability Based on Fuzzy Comprehensive Evaluation in Entrepreneurship Education System
}

\author{
Rongyan Jia ${ }^{1}$ \\ Lina Yuan ${ }^{2}$ \\ Hebei University of Science and Technology \\ Hebei University of Science and Technology
}

\begin{abstract}
Facing the complicated market environment, the entrepreneurial practice of college students shows that the entrepreneurial executive ability is relatively weak. This paper aims to analyze entrepreneurial executive ability by AHP and relevant fuzzy evaluation. Through discussing factors which affects executive ability, a new definition of executive ability based on process is put forward, and accordingly, evaluation index system of executive ability is constructed. Weight coefficient of index system has been obtained by the combined method of questionnaire investigation and AHP, and the relevant fuzzy evaluation model has been established. Using two-dimensional quadrant analysis and relevant coefficient analysis, selecting approaches and the ways of improved object are pointed out, and the concrete suggestions have been put forward.
\end{abstract}

\section{Keywords}

Entrepreneurship Education • Executive Ability $\bullet$ Evaluation Index $・$ Fuzzy Comprehensive Evaluation • Process Management.

\footnotetext{
* This work is supported by 18455321D (Science and Technology Foundation of Hebei Province which title is "Research on Enhancing Sustainable Innovation Capacity of Innovative Enterprises"), SD181034 (Hebei Provincial Department of Education Humanities and Social Sciences Research Project which title is "Research on development of Strategic New Emerging Industries in Hebei Province under the Background of Synergy Development of Beijing, Tianjin and Hebei"), CX2017Y04 (Institute of Science and Technology of Hebei University of Science and Technology: Innovation and Entrepreneurshiporiented Teaching Reform Research whose title is "Technology and Economic Evaluation of Innovation and Entrepreneurship Project"), 2018Y19 (Institute of Science and Technology of Hebei University of Science and Technology: Reform of "Statistics" Course, "Statistics" in the Application of Innovation and Entrepreneurship and Teaching Reform Research).

${ }^{1}$ Correspondence to: Rongyan Jia (MSc), College of Economics \& Management, Hebei University of Science and Technology, Hebei, Shijiazhuang 050018, China. Email: 438803752@qq.com

${ }^{2}$ College of Economics \& Management, Hebei University of Science and Technology, Hebei, Shijiazhuang 050018, China. Email: 51868667@qq.com
}

Citation: Jia, R. Y. \& Yuan, L. N., Research on Entrepreneurial Executive Ability Based on Fuzzy Comprehensive Evaluation in Entrepreneurship Education System. Educational Sciences: Theory \& Practice, 18(5), 1150-1159. http://dx.doi.org/10.12738/estp.2018.5.016 
In 2017, the United Nations Educational, Scientific and Technological Organization Asia-Pacific Education Innovation Program Entrepreneurship Education Conference-Entrepreneurship Education for Global Prosperity was held in Philippines. The spokesperson of the opening ceremony pointed out that the key of innovation capability was entrepreneurship education, and it was the responsibility of educators to help students develop their entrepreneurial potential to meet the needs of the 21 st century. Inspiring, confident and capable graduates are the key to national development. Governments, universities, businesses and organizations around the world recognize the important role of entrepreneurship education in promoting global sustainable development.

The innovation and entrepreneurship education system of college students are based on entrepreneurial knowledge and the entrepreneurial ability. College students get entrepreneurial ability by learning the basic knowledge of entrepreneurship and training the basic qualities and awareness of entrepreneurship. After having the quality and ability to start a business, it has entered the stage of entrepreneurship. To give full play to the entrepreneurial advantages of college students, we must pay attention to improving the entrepreneurial executive ability of college students. Execution will determine the success of entrepreneurship, and strong execution is the ultimate guarantee for business success.

In the practice of entrepreneurship education system, many wonderful scheme and ultimate executive effect of decision are poorer than imaging, if there is not a set of powerful executive system and only according to rules and regulations, it will be even worse. In this paper, the evaluation model of college students' entrepreneurial execution ability is put forward.

At the beginning of 2003, Execution-the Discipline of Getting Things Done came out authorized by Larry Bossidy and Ram Charan and the authors pointed out clearly that executive ability is the hinge for enterprises existing, developing, even pursuing excellence, and demand closely integrates manpower, strategy, and operation of organization together, which started the climax of researching executive ability (Ahrens \& Dent, 2004; Hoła et al., 2013). Executive ability is considered as the leadership by Paul Hersey, while it is defined as the ability for enterprises or departments accomplishing the decision goal, and many principled proposals have been put forward from the aspects of promoting and cultivating the qualities of executor, strengthening and improving the system of enterprise management, constructing corporation culture to illustrate (Czarnigowska \& Sobotka, 2013; Chiwamit, Modell \& Scapens, 2016). However, the following aspects are not involved in the available literature:

(1) The definition of the concept of executive ability does not roundly, objectively, systematically reveal the root cause for resulting poor execution. Accordingly, the optimal management could not be deeply discussed from the aspects of structure, operation, function, performance and information feedback.

(2) Fundamental research of executive ability should be highlighted, which includes formulating the decision-making objective of enterprise, and the system of management, the specification of work mechanism, and constructing enterprise culture, etc.

(3) Integrated evaluation system of executive ability has not been formed. The aim of researching executive ability is promoting executive ability, whose key point is scientifically evaluating executive ability. It is very 
important to complete the evaluation index system of execution, which has not yet been referred to in the available literature.

(4) The clear guidance for enterprise enhancing and improving executive ability is insufficient. According to On Contradiction and the theory of relativity, it is impossible for enterprise having serious defects or problems in every aspect, only relatively weak in a certain way (Ahrens \& Khalifa, 2015; Alcouffe, Berland \& Levant, 2008), otherwise, enterprises may have already bankrupted or closed down, even don't exist. It is the fundamental objective of studying executive ability to utilize the evaluation results of executive ability for guiding and helping enterprises to find weak line and improve it, thereby promoting competitive edge. However, because of not establishing evaluation system, it is impossible utilizing the evaluation results to guide and improve enterprise specially (Burkert \& Lueg, 2013; Alon \& Dwyer, 2016; Ansari, Fiss \& Zajac, 2010).

\section{The definition of executive ability}

Executive ability ought to be a generalized concept, not only including specific executive process of objective task, but also stretching upward to the plan of decision-making and task of the enterprise, and expanding downward to the evaluation and acceptance of the executive effects, finally forming the concept of PDCA dynamic circulation from planning, operation, inspection and evaluation, information feedback, continuous improvement and enhancement (Ansari, Reinecke \& Spaan, 2014). Executive ability could be divided into three stages of executive foundation, executive process, executive result, which are established by the stage of executive foundation, accomplished by executive process, and the information is fed back to the evaluation stage of executive result which improve related objects and influencing factors, then the next round of circulation begins. Executive ability exactly refers to the comprehensive ability expressed by the three stages, as shown in figure 1:

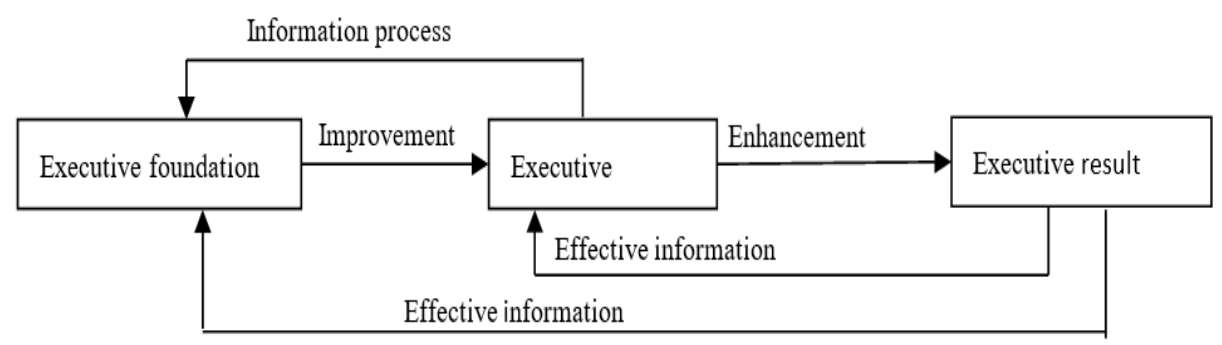

Figure 1. The model of the concept of executive ability

\section{Executive foundation}

Executive foundation, called fundamental execution, includes the objective task of enterprise, quality of enterprise, quality of individual and enterprise culture which are the most fundamental four influencing factors of executive ability for enterprise. 
(1) Objective Task: Only the objective task of specific, reasonable and clear, can executors correctly comprehend and take measures to carry out thoroughly. The objective task of obscure and unpractical can only result poorly execution, even worse.

(2) Quality of Enterprise: To ensure the objective task of enterprise implementing smoothly, the process of basic system is processed. It includes reasonable organization structure, scientific working process, transparent management system, effective incentive-restricted mechanism and efficient mechanism for information transfer, etc.

(3) Quality of Individual: It refers to the quality of executor, and knowledge, skills, experience, innovation and training condition that executors should possess of.

(4) Culture of Executive Ability: Cultivating the atmosphere of executive ability is stressed in the philosophy of enterprise culture and all staff regard executive ability as the highest criterion and ultimate goal for all action, concealing in the thinking activities of staff, showing in the action of the staff.

\section{Executive process}

Executive Process refers to the comprehensive ability of the process for organizing, coordinating, controlling objective task and implementing.

(1) Process Organizing: For the process effectively organized, correctly understanding objective task, comprehending connotation is required. Then, the process is resolved and refined so that grassroots are carried out.

(2) Process Coordinating: Executors actively taking measures are needed when emergency or some unpredictable factors coming in the executive process. At more time, uniting and coordinating several departments and different resources to deal are required.

(3) Process Monitoring: The monitoring for executive process is embodied in two aspects of supervision and inspection. Objective task is known in time and the first-hand information is grasped in the executive process by carrying out overall process and all directs, supervising and inspecting in real time. On the one hand, the problems can be found and solved promptly. On the other hand, the leaders can be feedback, controlling from the whole situation of enterprise.

\section{Executive result}

Executive Result: The final result for objective task of enterprise obtaining is referred, through three aspects of executive strength, executive efficiency, executive quality to evaluate and measure.

(1) Executive Strength: The determined degree of finishing objective task and the degree of finishing task are referred. Comprehensive assessment is conducted through attitude of working and the degree of finishing task. 
(2) Executive Efficiency: The degree of time for finishing objective task and if according to the planning made in advance or not to carry out smoothly and boost are referred, not tight at first but loose afterwards or inversely, which are likely to result in poor executive effect.

(3) Executive Quality: The final quality and effect obtained of finishing objective task is referred, and the assessment can be done through the third-party evaluating quality and according to the assessment standard made in advance.

\section{The structure of evaluation index system of executive ability}

According to the writer analyzing the concept of executive ability, the structure of evaluation index system of executive ability is shown as form 1 . The data was obtained by questionnaire and analyzed by AHP and dual method. Weight coefficient of index system has been obtained, as shown in Table 1.

\section{Fuzzy comprehensive evaluation model of executive ability for enterprise}

Because the index system established in this article is a multilevel structure and the executive ability of enterprise consists of executive foundation, executive process and executive result; secondary fuzzy comprehensive evaluation method has been adopted to calculate, a case analysis of executive ability:

(1) The Ranking Score of Comment Set

Comment Set $B=\left\{b_{1}, b_{2}, \ldots, b_{n}\right\}$, in which random $b_{j}$ is a fuzzy subset of set $\mathrm{B}$, is divided into five levels. The comment set B of executive ability of enterprise is \{Very Good, Pretty Good, Fair, Bad, Very Bad\}. To make it easy to identify the degree of comprehensive evaluation result, based on attitude measuring technologyLikert scale, the score of every rank is $\{100,80,60,30,0\}$ according to fuzzy comprehensive evaluation method.

(2) The Membership of Evaluation Indicator

Supposing the number of specialists attending evaluation is $N$, among which the number of regarding evaluation indicators are very good, pretty good, fair, bad and very bad, respectively $N_{1}, N_{2}, N_{3}, N_{4}$ and $N_{5}$. According to the calculating of fuzzy statistics, the member of indicator are $N_{1} / N, N_{2} / N, N_{3} / N, N_{4} / N$ and $N_{5} / N$, marke $\mathrm{d} r_{i j}$, showing the member of comment rank jor indicator $C_{i}$ is $r_{i j}$.

(3) Fuzzy Comprehensive Evaluation

The initial model of Fuzzy Comprehensive Evaluation is $B=A \cdot R=\left\{b_{1}, b_{2}, . ., b_{m}\right\}$, among which $A$ is Weighting Set, and Ris Member Set.

$$
b_{j}=\stackrel{i=1}{n}\left(a_{i} \wedge r_{i j}\right) \quad(j=1,2, \cdots, m)
$$


Jia, Yuan / Research on Entrepreneurial Executive Ability Based on Fuzzy Comprehensive Evaluation in Entrepreneurship...

Table 1

Evaluation Index System of Executive Ability, Weight Coefficient of Index System and Evaluation Result

\begin{tabular}{|c|c|c|c|c|c|}
\hline \multicolumn{2}{|c|}{ First level index } & \multicolumn{2}{|c|}{ Secondary index } & \multicolumn{2}{|l|}{ Third level index } \\
\hline $\begin{array}{l}\text { The name of } \\
\text { index }\end{array}$ & Weights & $\begin{array}{l}\text { The name of } \\
\text { index }\end{array}$ & Weights & The name of index & Weights \\
\hline \multirow{17}{*}{$\begin{array}{l}\text { Executive } \\
\text { Foundation } \\
(63.33)\end{array}$} & \multirow{17}{*}{0.3673} & \multirow{3}{*}{$\begin{array}{c}\text { Objective } \\
\text { Task } \\
(67.94) \\
\end{array}$} & \multirow{3}{*}{0.2450} & Concreteness (71.00) & 0.1636 \\
\hline & & & & Rationality (70.33) & 0.3940 \\
\hline & & & & Standard Clarity (64.67) & 0.4425 \\
\hline & & \multirow{5}{*}{$\begin{array}{c}\text { Quality of } \\
\text { Individual } \\
(61.51)\end{array}$} & \multirow{5}{*}{0.3298} & Professional Knowledge (69.67) & 0.1817 \\
\hline & & & & Professional Skill (56.67) & 0.3866 \\
\hline & & & & Professional Experience (66.67) & 0.2278 \\
\hline & & & & Innovation Ability (59.00) & 0.0687 \\
\hline & & & & Team Spirit (57.00) & 0.1351 \\
\hline & & \multirow{7}{*}{$\begin{array}{c}\text { Quality of } \\
\text { Enterprise } \\
(61.70)\end{array}$} & \multirow{7}{*}{0.3298} & Organization Structure (64.67) & 0.0958 \\
\hline & & & & Management System (62.67) & 0.2113 \\
\hline & & & & Working Process (62.53) & 0.2636 \\
\hline & & & & Incentive and Restraint Mechanism (63.33) & 0.1360 \\
\hline & & & & $\begin{array}{l}\text { Dividing Work andAuthorization Mechanism } \\
(61.00)\end{array}$ & 0.0865 \\
\hline & & & & Performance Assessment Mechanism (55.67) & 0.1475 \\
\hline & & & & Information Delivering Mechanism (62.00) & 0.0593 \\
\hline & & \multirow{2}{*}{$\begin{array}{c}\text { Culture of } \\
\text { Executive } \\
\text { Ability } \\
(63.47) \\
\end{array}$} & \multirow[b]{2}{*}{0.0954} & Sense of Identity Belonging (62.67) & 0.4000 \\
\hline & & & & Corporate Vision (64.00) & 0.6000 \\
\hline \multirow{6}{*}{$\begin{array}{l}\text { Executive } \\
\text { Process } \\
(67.31)\end{array}$} & \multirow{6}{*}{0.4425} & \multirow{2}{*}{$\begin{array}{c}\text { Process } \\
\text { Organizing } \\
(69.08) \\
\end{array}$} & \multirow[b]{2}{*}{0.4425} & Policy Comprehension (71.67) & 0.7614 \\
\hline & & & & Objective Decomposing (68.45) & 0.2386 \\
\hline & & \multirow{2}{*}{$\begin{array}{c}\text { Process } \\
\text { Coordinating } \\
(67.97) \\
\end{array}$} & \multirow[b]{2}{*}{0.2940} & Flexible Adaption (81.41) & 0.5823 \\
\hline & & & & Unity and Cooperation (61.75) & 0.4177 \\
\hline & & Process & \multirow[b]{2}{*}{0.2635} & Supervision of Process (78.45) & 0.5119 \\
\hline & & $\begin{array}{l}\text { Monitoring } \\
(63.60)\end{array}$ & & Inspection of Process (65.64) & 0.4871 \\
\hline \multirow{6}{*}{$\begin{array}{l}\text { Executive } \\
\text { Result } \\
(67.26)\end{array}$} & \multirow{6}{*}{0.1903} & Executive & \multirow[b]{2}{*}{0.2921} & Working Attitude (72.38) & 0.5319 \\
\hline & & $\begin{array}{l}\text { Strength } \\
(68.29)\end{array}$ & & Performance (63.18) & 0.4681 \\
\hline & & Executive & \multirow[b]{2}{*}{0.3139} & Speed of execution (68.55) & 0.6847 \\
\hline & & $\begin{array}{c}\text { Efficiency } \\
(69.44)\end{array}$ & & Project Boosting (60.11) & 0.3153 \\
\hline & & \multirow{2}{*}{$\begin{array}{c}\text { Executive } \\
\text { Quality } \\
(64.76)\end{array}$} & \multirow[b]{2}{*}{0.3940} & Evaluating Quality (56.13) & 0.2869 \\
\hline & & & & Inspecting Quality (62.77) & 0.7131 \\
\hline
\end{tabular}

Three level of Fuzzy Comprehensive Evaluation Modelhas been obtained through dividing factors once only. The equation is

$$
B=A \circ R=A \circ\left(\begin{array}{ccc}
A_{1} & 0 & R_{1} \\
\vdots & \vdots & \vdots \\
A_{n} & 0 & R_{n}
\end{array}\right)
$$

The block diagram of evaluation model is shown as figure 2: 


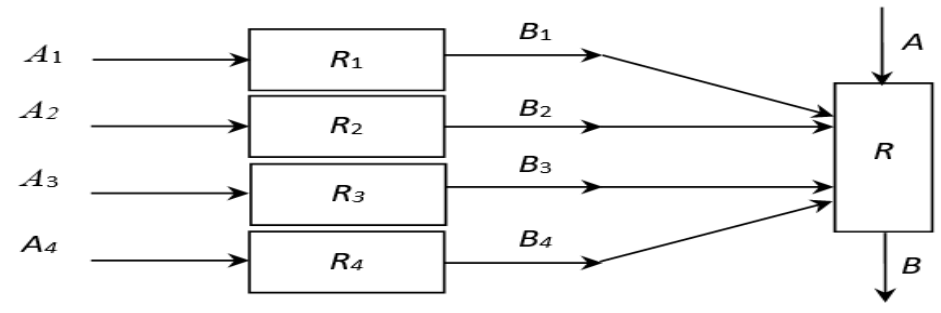

Figure 2. Secondary Level of Fuzzy Comprehensive Evaluation Model

As for figure 2,

$A=\left\{A_{1}, A_{2}, A_{3}, A_{4}\right\}, A_{1}=\left\{a_{11}, a_{12}, a_{13}\right\}, A_{2}=\left\{a_{21}, a_{22}, a_{23}, a_{24}, a_{25}\right\}$,

$A_{3}=\left\{a_{31}, a_{32}, a_{33}, a_{34}, a_{35}, a_{36}, a_{37}\right\}, A_{4}=\left\{a_{41}, a_{42}\right\}$

$$
\begin{aligned}
& R=\left(\begin{array}{l}
B_{1} \\
B_{2} \\
B_{3} \\
B_{4}
\end{array}\right)=\left(r_{i j}\right) \quad, R_{1}=\left(\begin{array}{llllllll}
r_{11} & r_{12} & r_{13} & r_{14} & r_{15} \\
r_{21} & r_{22} & r_{23} & r_{24} & r_{25} \\
r_{31} & r_{32} & r_{33} & r_{34} & r_{35}
\end{array}\right), \quad R_{2}=\left(\begin{array}{llllll}
r_{41} & r_{42} & r_{43} & r_{44} & r_{45} \\
r_{51} & r_{52} & r_{53} & r_{54} & r_{55} \\
r_{61} & r_{62} & r_{63} & r_{64} & r_{65} \\
r_{71} & r_{72} & r_{73} & r_{74} & r_{75} \\
r_{81} & r_{82} & r_{83} & r_{84} & r_{85}
\end{array}\right) \text {, } \\
& R_{3}=\left(\begin{array}{lllll}
r_{91} & r_{92} & r_{93} & r_{94} & r_{95} \\
r_{101} & r_{102} & r_{103} & r_{104} & r_{105} \\
r_{111} & r_{112} & r_{113} & r_{114} & r_{115} \\
r_{121} & r_{122} & r_{123} & r_{124} & r_{125} \\
r_{131} & r_{132} & r_{133} & r_{134} & r_{135} \\
r_{141} & r_{142} & r_{143} & r_{144} & r_{145} \\
r_{151} & r_{152} & r_{153} & r_{154} & r_{155}
\end{array}\right), R_{4}=\left(\begin{array}{llllll}
r_{161} & r_{162} & r_{163} & r_{164} & r_{165} \\
r_{171} & r_{172} & r_{173} & r_{174} & r_{175}
\end{array}\right)
\end{aligned}
$$

$B=A \cdot R=\left\{b_{1}, b_{2}, \cdots, b_{m}\right\}, B_{1}=A_{1} \cdot R_{1}, B_{2}=A_{2} \cdot R_{21}, B_{3}=A_{3} \cdot R_{3}, B_{4}=A_{4} \cdot R_{4}$

(4) Determining comment rank and calculating total points of significance

According to the maximum membership principle, the comment rank is determined and adjusted in the following way:

Supposing $b_{\mathrm{k}}$ is the maximum of $B$, if

$$
\sum_{j=1}^{k-1} b_{j} \geq \frac{1}{2} \sum_{j=1}^{5} b_{j} \geq \sum_{j=k+1}^{5} b_{j}, \text { or, } \sum_{j=k+1}^{5} b_{j} \geq \frac{1}{2} \sum_{j=1}^{5} b_{j} \geq \sum_{j=1}^{k-1} b_{j}
$$

The rank will move downward or upward. Then the parameter of total points is calculated. The computational formula is followed:

$$
\mu=\frac{\sum_{j=1}^{5} \mu_{v}(j) b_{j}}{\sum_{j=1}^{5} b_{j}}
$$


According to the above calculating process, the writer investigated and evaluated certain executive ability of enterprise, selecting twenty individuals. Table 1 shows the final evaluating results. From the result of assessment in the table 1, it is obvious that the medium-sized state-owned enterprise used to be glorious and now operation is going worse and worse.

\section{The object of executive ability improving}

Through analyzing the final evaluated points of executive ability, the key factor which has impact on executive ability of enterprise is found, and the key information which is helpful to choose the object for improving is extracted, and the feedback mechanism of information is established by the information which data has obtained, improving operational mechanism or problems in the management, and accordingly the approach and measures of cultivating and promoting executive ability has been found. Generally, using correlation coefficient method and two-dimensional quadrant analysis which determines the object of improvement, the numerical value of correlation coefficient is analyzed.

\begin{tabular}{|c|c|c|}
\hline hirh & IV: Value<63.13, Weight $>0.0603$ & I: Value $>63.13$, Weight $>0.0603$ \\
\hline $\begin{array}{l}\text { Comprehensive } \\
\text { Weight }\end{array}$ & $\begin{array}{l}\text { Professional Skill, Management } \\
\text { System, Working Process }\end{array}$ & $\begin{array}{l}\text { Rationality, Standard Clarity, } \\
\text { Professional Knowledge, } \\
\text { Professional Experience }\end{array}$ \\
\hline Coefficient & III: Value $<63.13$, Weight $<0.0603$ & II: Value $>63.13$, Weight $<0.0603$ \\
\hline low & $\begin{array}{l}\text { Innovation Ability, Team Spirit, Dividing } \\
\text { Work and Authorization Mechanism, } \\
\text { Performance Assessment Mechanism, } \\
\text { Information Delivering Mechanism, } \\
\text { Sense of Identity Belonging }\end{array}$ & $\begin{array}{l}\text { Concreteness, Organization Structure, } \\
\text { Incentive and Restraint Mechanism, } \\
\text { Corporate Vision }\end{array}$ \\
\hline
\end{tabular}

Figure 3. The results of quadrant method for executive foundation

According to survey data, abscissa is determined as average value of indicator evaluation, and ordinate is determined as average value of synthesized coefficient of indicator. The four level indicator of executive foundation, executive process, executive effect has been calculated, and $\overline{E F I}=63.15, \overline{w_{f}}=0.0588, \overline{E P I}=$ $71.23, \overline{w_{p}}=0.1667, \overline{E R I}=63.85, \overline{w_{R}}=0.1667$. Taking executive foundation for example, The calculating result is shown as figure:

The coefficient of association has been calculated by using SPSSand can get: 
(1) The rank of correlation for two level of executive ability is successively executive process (0.790976), executive result $(0.288453)$, executive foundation $(0.185245)$.

(2) The rank of correlation for four level index of executive foundation is successively Professional Skill(0.813404),Corporate Vision(0.806633), Dividing Work and Authorization Mechanism (0.759699), Sense of Identity Belonging(0.73909), Performance Assessment Mechanism (0.731439), Innovation Ability (0.716623), Management System (0.700765), Concreteness (0.659428), Rationality (0.631649), Team Spirit (0.60854), Working Process (0.590542), Standard Clarity(0.563356), Professional Experience (0.545405), Incentive and Restraint Mechanism(0.54458), Organization Structure (0.532018), Professional Knowledge (0.52262), Information Delivering Mechanism (0.227055).

(3) The rank of correlation for four level indexes of executive process is successively Policy Comprehension (0.915093), Objective Decomposing (0.851286), Flexible Adaption (0.900924), Unity and Cooperation (0.833225), Supervision of Process (0.483014), Inspection of Process (0.462495).

(4) The rank of correlation for four level indexes of executive result is successively Performance (0.865171), Project Boosting (0.842919), Evaluating Quality (0.832123), Inspecting Quality (0.789976), Working Attitude (0.770277362), Speed of execution (0.751019).

Using two-dimensional quadrant analysis and relevant coefficient analysis, the factors which are needed badly to improve and enhance the weak link for enterprise have been discussed and summarized, including Professional Skill, Working Process and Management System in the Executive Foundation, Supervision of Process, Inspection of Process and Unity and Cooperation in the Executive Process, Performance, Project Boosting and Inspecting Quality in the Executive Result.

\section{Conclusion}

In the practice of entrepreneurship education, enterprise competitiveness is determined by Executive Result. Only by finding and eliminating the defects that restrict the effective implementation of the enterprise can the company run smoothly. System Management, TQM, Customer Satisfaction Management are supplied in this article, defining the executive ability, and assessment indicator system of executive ability for enterprise and the relevant fuzzy evaluation model have been established, and choosing approach for the object of executive ability improving has been put forward, trying to master the core of enterprise and help college students accomplish the goal of promoting executive ability.

\section{References}

Ahrens, T., \& Dent, J. F. (1998). Accounting and organizations: realizing the richness of field research. Journal of Management Accounting Research, 10, 1. 
Ahrens, T., \& Khalifa, R. (2015). The impact of regulation on management control: Compliance as a strategic response to institutional logics of university accreditation. Qualitative Research in Accounting \& Management, 12(2), 106-126. https://doi.org/10.1108/QRAM-04-2015-0041

Alcouffe, S., Berland, N., \& Levant, Y. (2008). Actor-networks and the diffusion of management accounting innovations: A comparative study. Management Accounting Research. 19(1), 1-17. https://doi.org/10.1016/j.mar.2007.04.001

Alon, A., \& Dwyer, P. D. (2016). SEC's acceptance of IFRS-based financial reporting: an examination based in institutional theory. Accounting Organizations \& Society, 48, 1-16. https://doi.org/10.1016/j.aos.2015.11.002

Ansari, S., Fiss, P. C., \& Zajac, E. J. (2010). Made to fit: how practices vary as they diffuse. Academy of Management Review. 35(1), 67-92. https://doi.org/10.5465/AMR.2010.45577876

Ansari, S., Reinecke, J., \&Spaan, A. (2014). How are practices made to vary? Managing practice adaptation in a multinational corporation. Social Science Electronic Publishing, 35, 1313-1341. https://doi.org/10.1177/0170840614539310

Burkert, M., \& Lueg, R. (2013). Differences in the sophistication of value-based management-the role of top executives. Management Accounting Research, 24(1), 3-22. https://doi.org/10.1016/j.mar.2012.10.001

Chiwamit, P., Modell, S., \& Scapens, R. W. (2016). Regulation and adaptation of management accounting innovations: The case of economic value added in Thai state-owned enterprises. Management Accounting Research, 2, 419-426. https://doi.org/10.1016/j.mar.2017.03.001

Czarnigowska, A., \& Sobotka A., (2013). Time-cost relationship for predicting construction duration. Archives of Civil and Mechanical Engineering, 13(4), 518-526. https://doi.org/10.1016/j.acme.2013.05.004

Hoła, B., Polak, A., Skibniewski, M., Sawicki, M., Gawron, K., \& Morka M. (2013). A Knowledge Management System in a Construction Enterprise. Wroclaw University of Technology. 